\title{
Accommodative Relaxation by Extending the Viewing Distance through the Simple Optical Design of a Double-Mirror System
}

\author{
Shang-Min Yeh ${ }^{1,2}$, Hui-Rong Su ${ }^{1}$, Chi-Hung Lee ${ }^{3}$, Yu-Jung Chen ${ }^{4,5}$ and Shuan-Yu Huang ${ }^{1,2, *}$ \\ 1 Department of Optometry, Chung Shan Medical University, Taichung 402, Taiwan; \\ ysm@csmu.edu.tw (S.-M.Y.); leah86037@gmail.com (H.-R.S.) \\ 2 Department of Ophthalmology, Chung Shan Medical University Hospital, Taichung 402, Taiwan \\ 3 Department of Electrical Engineering, Feng Chia University, Taichung 407, Taiwan; chihlee@fcu.edu.tw \\ 4 Ph.D. Program of Electrical and Communications Engineering, Feng Chia University, Taichung 407, Taiwan; \\ yuhung@mail.dyu.edu.tw \\ 5 Department of Optometry, Da-Yeh University, Changhua 515, Taiwan \\ * Correspondence: syhuang@csmu.edu.tw
}

Citation: Yeh, S.-M.; Su, H.-R.; Lee, C.-H.; Chen, Y.-J.; Huang, S.-Y.

Accommodative Relaxation by Extending the Viewing Distance through the Simple Optical Design of a Double-Mirror System. Appl. Sci. 2021, 11, 6979. https://doi.org/ 10.3390/app11156979

Academic Editor: George Rachiotis

Received: 29 June 2021

Accepted: 26 July 2021

Published: 29 July 2021

Publisher's Note: MDPI stays neutral with regard to jurisdictional claims in published maps and institutional affiliations.

Copyright: (c) 2021 by the authors. Licensee MDPI, Basel, Switzerland. This article is an open access article distributed under the terms and conditions of the Creative Commons Attribution (CC BY) license (https:// creativecommons.org/licenses/by/ $4.0 /)$.

\begin{abstract}
Purpose: This paper discusses the accommodative relaxation of myopic adults using a simple double-mirror design. This optical design can extend the viewing distance to $2.285 \mathrm{~m}$ and can magnify the image up to 3.386 times, and it results in the accommodative relaxation of a single human eye. By using this optical design, accommodative relaxation may improve eye fatigue and, furthermore, it may delay the progression of myopia. Method: This study recruited 32 subjects with an average age of $20.8 \pm 0.95$ years old. After an examination of their refractive status, disposable contact lenses with a corresponding refractive error were fitted, and the dynamic accommodative response and change in pupil size were measured by using an open-field autorefractor. The subjects gazed at two different viewing distances. First, they gazed at a real object, which was placed $0.4 \mathrm{~m}$ in front of them. Second, the subjects gazed at a virtual image through a double-mirror system at a distance of $2.285 \mathrm{~m}$. The dynamic accommodative responses and pupil size data were collected under these two viewing distance conditions. Results: When the subjects gazed at a real object that was $0.4 \mathrm{~m}$ away, or a virtual image that was $2.285 \mathrm{~m}$ away, the mean value of the accommodative response was $1.69 \pm 0.31 \mathrm{D}$ or $0.11 \pm 0.05 \mathrm{D}$, and the pupil size was $3.79 \pm 0.49 \mathrm{~mm}$ or $4.09 \pm 0.72 \mathrm{~mm}$, respectively. The accommodative response decreased, and the pupil size increased when using the double-mirror system, and therefore, accommodative relaxation can be achieved by using this new optical design. Conclusions: In the present study, we first successfully proposed a simple optical design to relax the accommodation, and the fluctuations of the accommodation response were stable, with an extended viewing distance of $2.285 \mathrm{~m}$. This design may be applied for the improvement of visual function in applications such as the reduction of asthenopia and the control of myopia.
\end{abstract}

Keywords: accommodative relaxation; double-mirror design; progression of myopia; accommodative response; pupil size; fluctuations

\section{Introduction}

With the advancement of science and technology, people have changed their reading habits [1-5] and have been more exposed to digital products. As a result, the need for near work has increased, and accommodation has been considered to be involved in the occurrence and progression of myopia [6-11]. After using digital devices at a close distance over a long period of time, symptoms such as eye fatigue, dry eyes, double vision, blurred vision, and headaches tend to occur [12]. In the early years, the symptoms were collectively known as 'Computer Vision Syndrome (CVS)' [13,14]. With the popularization of electronic products in recent years, the term has been changed to 'Digital Eye Strain (DES)', which is caused by working at close distances $[15,16]$. 
Plenty of evidence suggests that the lag in accommodation is related to myopia. At the same stimulus distance, myopic people have a higher accommodation lag than emmetropic people. In addition, compared to emmetropic children, myopic children read at a closer proximity, which may lead to an increase in accommodation lag due to the increased demand for accommodation. When reading at closer proximity, a larger accommodation lag is more likely to cause the progression of myopia. An extended viewing distance can also stabilize the accommodation fluctuation $[17,18]$.

Remote accommodation is a training method that induces periodic pupil constriction, thereby improving the eyesight of myopic children. A previous study used LCD screens to simulate changes in two gazing positions $(70 \mathrm{~cm}$ and $25 \mathrm{~cm}$ ) in an attempt to improve the eyesight of myopic children [19].

Tsuneto et al. presented the effects of accommodative relaxation using far point shift stimuli to improve visual function and to reduce eye fatigue [20]. In the present study, we first proposed a simple optical design that consists of a concave mirror and a convex mirror to extend viewing distance from $0.4 \mathrm{~m}$ to $2.285 \mathrm{~m}$ so that the accommodation can be relaxed. The accommodation fluctuation also presented stably. In this study, the accommodative response could be reduced for subjects aged between 18 to 22 years old, and we expect that accommodative relaxation could be also achieved for school children. Furthermore, it may be applied to slow down the progression of myopia and to mitigate the problems caused by near work.

\section{Method}

\subsection{Design of the Proposed Double-Mirror System}

In the present study, we first proposed the application of a double-mirror system for extending viewing distance. The system consisted of two mirrors, one concave and one convex. The convex mirror first reduces the image and enlarges the field of view, and the concave mirror then enlarges the image. Finally, the image is viewed by the human eye.

The diopters of the two mirrors were $+2.83 \mathrm{D}$ and $-2.83 \mathrm{D}$, respectively. The distance between the human eye and the concave mirror was $400 \mathrm{~mm}$; the distance between the concave mirror and the convex mirror was $145 \mathrm{~mm}$; and the distance between the convex mirror and the object was $280 \mathrm{~mm}$.

The imaging of the double-mirror system can be illustrated through the example of thin lens imaging. A concave mirror is equivalent to a convex lens, and a convex mirror is equivalent to a concave lens for simulation. Based on this, the distance from the eye to the image can be up to $2.285 \mathrm{~m}$, and the paraxial magnification of the image is $3.386 \mathrm{X}$, as shown in Figure 1.

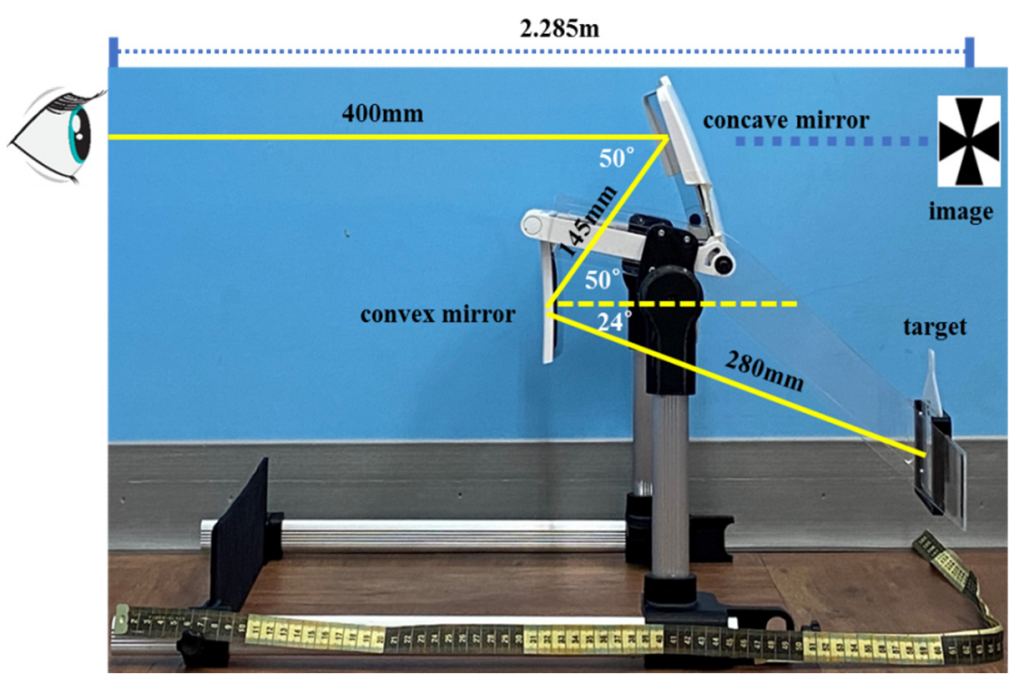

Figure 1. Design of the double-mirror system and simulation of the image position. 
The image observed by a user is a target of $10 \mathrm{~mm} \times 10 \mathrm{~mm}$, which is at the rightbottom side of the double-mirror system and can be analyzed using the optical software, LightTools, illustrated in Figure 2 [21]. In the simulation, the concave mirror is of $140 \mathrm{~mm}$ wide and $70 \mathrm{~mm}$ high, with a curvature radius of $706.7 \mathrm{~mm}$ in the $\mathrm{y}-\mathrm{z}$ plane and $745 \mathrm{~mm}$ in the $x-z$ plane. The convex mirror is also $140 \mathrm{~mm}$ wide and $70 \mathrm{~mm}$ high, with a spherical curvature radius of $706.7 \mathrm{~mm}$. When viewing the target through the double-mirror system, both eyes rotate to a vergence angle of $1.62^{\circ}$ and can observe an enlarged image at $2285 \mathrm{~mm}$ with a size of $0.254 \mathrm{~mm}$ wide and $0.195 \mathrm{~mm}$ high, as shown in Figure 3a,b for the left and right eyes, respectively. A directly viewed image of the same target at $2285 \mathrm{~mm}$ is $0.075 \mathrm{~mm}$ wide and is shown in Figure $3 \mathrm{c}$ for comparison. The simulations indicate that the magnification of the double system is around $3.386 \mathrm{X}$ along the horizontal direction and $2.6 \mathrm{X}$ along the vertical direction. In fact, these values are obtained by assuming the pupil distance to be $65 \mathrm{~mm}$ and can vary significantly for different pupil distances. Besides the magnification difference between the horizontal and the vertical axes, directions needs to be improved for further applications.

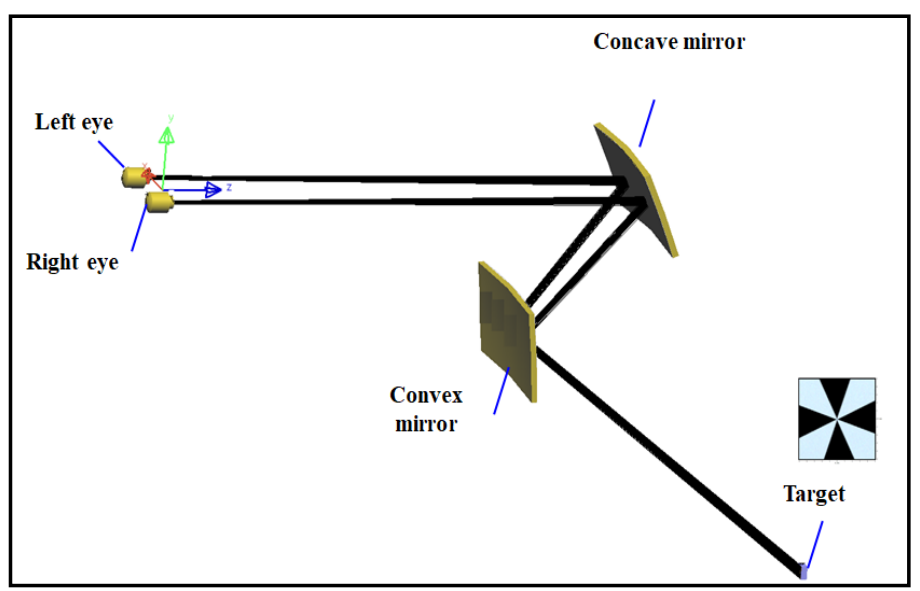

Figure 2. Optical layout of the double-mirror system built in the optical software, LightTools.
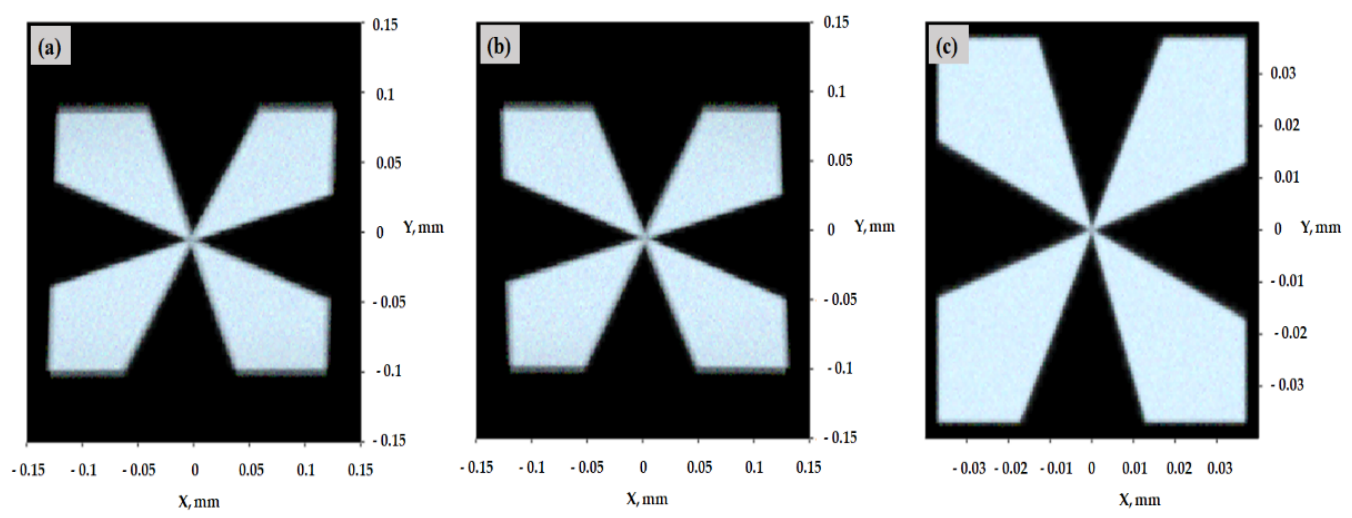

Figure 3. Simulated images at the retina. The images viewed by (a) the left eye and (b) the right eye through the double-mirror system. (c) A directly viewed image of a target at $2285 \mathrm{~mm}$.

\subsection{Research Subjects}

The subjects of this study were recruited from the Chung Shan Medical University and the Da-Yeh University. Their ages ranged between 18 and 22 years, and the average age was $20.8 \pm 0.95$. The inclusion criteria were as follows: those who had no prior eye or systemic diseases, those with a spherical diopter ranging from $0 \mathrm{D}$ to $-5.00 \mathrm{D}$, those with an astigmatism diopter $\geq-2.00 \mathrm{D}$, those with binocular visual acuity $\geq 0.1 \log \mathrm{MAR}$, and those with normal binocular vision. 
Informed consent was obtained from all the subjects, and the experiment was conducted in accordance with the Declaration of Helsinki. Ethical approval was obtained from the Institutional Review Board of the Chung Shan Medical University Hospital (Taichung, Taiwan) (Approval number: CS2-18104).

\subsection{Research Process}

The experimental procedure included the following two steps: The first step was an examination of the basic visual function. Each subject received an initial examination to determine refractive status with an open-field autorefractor, visual acuity with a chartprojector, phoria with a cover test, and stereoscopic vision with a fly-stereopsis test. After the basic examination, disposable contact lenses were provided to the subjects with a corresponding refractive error (Cooper Vision, water content: 55\%, base arc: $8.6 \mathrm{~mm}$, diameter: $14.2 \mathrm{~mm}$ ).

The second step was to measure the subjects' dynamic accommodative responses and pupil sizes. Indoor brightness affects the pupil size. In the dark, the pupil size is larger. Because this optical design is for reading purposes, we measured the accommodative responses and pupil size according to the state of brightness. The luminance of the laboratory was about 588 lux (measured using a spectral light meter (optimum SRI 2000)). There were two viewing distances that were set for the experiment: (1) the subjects gazed at a real object that was placed at a distance of $0.4 \mathrm{~m}$, and (2) they gazed at a virtual image that was located at a distance of $2.285 \mathrm{~m}$ through the double-mirror system. An open-field autorefractor (Grand Seiko WAM WR-5500) was used to measure the dynamic accommodative responses and pupil sizes of the subjects. Each detection time was $30 \mathrm{~s}$, and the average value of the three measurements was taken. Only the data from the right eye were measured in the experiment, and the subjects were required to cover their left eye with a occlude covering. During detection, the subjects were allowed to blink naturally, but they were asked to maintain their gaze at the target. The unit of the accommodative response is a diopter (D), and the unit of the pupil size is $\mathrm{mm}$.

\subsection{Data Analysis}

The dynamic accommodative responses and the pupil sizes of the right eye were recorded on the computer. All of the data were analyzed using SPSS Statistics 21.0, and an independent sample $t$-test and paired sample $t$-tests were conducted for statistical analysis.

\section{Results}

\subsection{Accommodative Response and Pupil Size}

The accommodative responses and pupil sizes of the subjects when gazing at a real object at a viewing distance of $0.4 \mathrm{~m}$ are shown in Table 1 . The mean value of the accommodative response of the male subjects was $1.55 \pm 0.25 \mathrm{D}$, while that of the female subjects was $1.82 \pm 0.21 \mathrm{D}$.

Table 1. The baseline of the subjects.

\begin{tabular}{cccc}
\hline & \multicolumn{2}{c}{ Average (Standard Deviation) } & \multirow{2}{*}{$p$} \\
\cline { 2 - 3 } & Male $(\boldsymbol{N}=\mathbf{1 6})$ & Female $(\boldsymbol{N}=\mathbf{1 6})$ & \\
\hline Age (y/o) & $20.82 \pm 0.88$ & $20.81 \pm 1.08$ & 0.99 \\
Equivalent sphere (D) & $1.90 \pm 1.43$ & $2.17 \pm 1.46$ & 0.97 \\
Accommodative response (D) & $1.55 \pm 0.25$ & $1.82 \pm 0.21$ & 0.08 \\
Pupil size (mm) & $3.82 \pm 0.50$ & $3.67 \pm 0.55$ & 0.51 \\
\hline
\end{tabular}

The accommodation stimulus changed with the different viewing distances and resulted in an accommodative response. The viewing distance was converted into the accommodation stimulus, and the accommodation stimulus formula is expressed as follows:

$$
\operatorname{Ac}(\mathrm{D})=1 / \mathrm{d}(\mathrm{m})
$$


where $d$ is the viewing distance, which is measured in meters, and the unit of the accommodation stimulus is a diopter (D). The accommodative stimulus is $2.5 \mathrm{D}(1 / 0.4=2.5 \mathrm{D})$ when the viewing distance is $0.4 \mathrm{~m}$, and the measured data for all of the subjects were less than $2.5 \mathrm{D}$, dropping an average of $0.81 \mathrm{D}$. When the accommodative response is smaller than the accommodative stimulus, it is called the 'lag of accommodation', the expected value of which also varies with age. For 20-year-old adults, the expected value of the lag of accommodation is $0.75 \pm 0.64 \mathrm{D}$, and the lag of accommodation observed in this study was within the expected values [22].

The pupil size was measured for $30 \mathrm{~s}$, and then the mean value was calculated. The average pupil size of the male subjects was $3.82 \pm 0.50 \mathrm{~mm}$, while that of the female subjects was $3.67 \pm 0.55 \mathrm{~mm}$. The results showed that there is no significant gender difference $(p=0.51)$.

\subsection{Comparison of the Dynamic Accommodative Response and the Pupil Size at Different Viewing Distances}

This experiment set two viewing distances, namely, $0.4 \mathrm{~m}$ away from the object and $2.285 \mathrm{~m}$ in front of the subjects' eyes through the double-mirror system. The changes in dynamic accommodative response and pupil size were detected and compared, as shown in Figure 4. The results show that the mean value of the accommodative response was $1.69 \pm 0.31 \mathrm{D}$ when the viewing distance was $0.4 \mathrm{~m}$, while it was $0.11 \pm 0.05 \mathrm{D}$ when the viewing distance was $2.285 \mathrm{~m}$ through the double-mirror system, and the accommodative response showed a significant difference between gazing at $0.4 \mathrm{~m}$ and $2.285 \mathrm{~m}(p<0.001)$. The pupil size was $3.79 \pm 0.49 \mathrm{~mm}$ and $4.09 \pm 0.72 \mathrm{~mm}$ when the viewing distances were $0.4 \mathrm{~m}$ and $2.285 \mathrm{~m}$, respectively, and a significant difference was also found in the pupil size $(p<0.001)$.

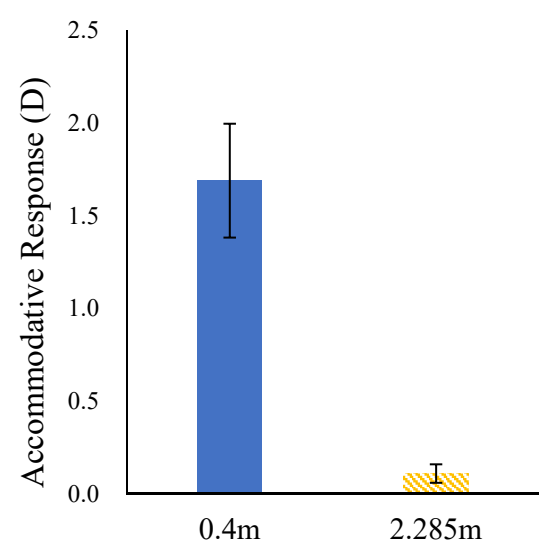

(a)

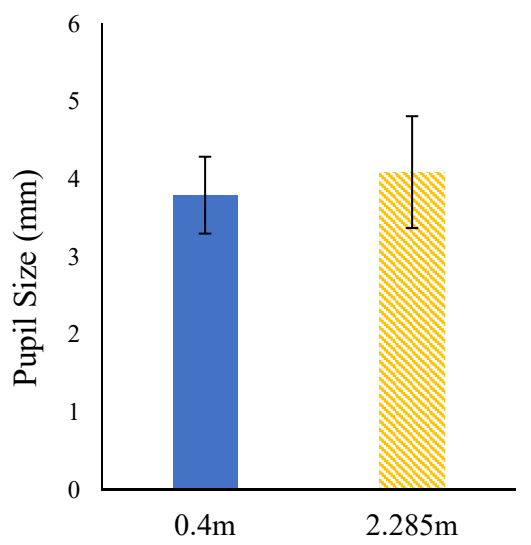

(b)

Figure 4. Comparison of (a) accommodative response and (b) pupil size at the two viewing distances of $0.4 \mathrm{~m}$ and $2.285 \mathrm{~m}$. 
As indicated by the above results, compared to the double-mirror system imaging, the accommodative response was larger and the pupil size was smaller when the subjects looked at a closer distance; on the other hand, when the viewing distance increased from $0.4 \mathrm{~m}$ to $2.285 \mathrm{~m}$ (double-mirror system imaging), the accommodation response was reduced, and the pupil size was enlarged. At a viewing distance of $2.285 \mathrm{~m}$, the accommodation could be relaxed by using the double-mirror system. The larger pupil size also reflects a reduction in accommodation.

To understand the effect of the double mirror system on the accommodative response, we compared the accommodative response of directly looking at the real object, looking at the virtual image through a single plane mirror at various viewing distances from $0.4 \mathrm{~m}$ to $2.285 \mathrm{~m}$, and looking at the virtual image at $2.285 \mathrm{~m}$ through the double-mirror system, as shown in Table 2 and Figure 5. Since the viewing distance of the double-mirror system is fixed, there is only one accommodative response at $2.285 \mathrm{~m}$. The accommodative response varies with the viewing distance in these three ways and is presented in Table 2. When the subjects were looking directly at the real object and looking at the image through a single plane mirror, the accommodative response decreased with the increase of the viewing distance from $0.4 \mathrm{~m}$ to $1.6 \mathrm{~m}$. When the viewing distance reached $2.285 \mathrm{~m}$, the accommodative response of the above two observation methods was very close to the accommodative response obtained by the double mirror system, which was about $0.11 \pm 0.05 \mathrm{D}$. The pupil size increased significantly with a viewing distance from $0.4 \mathrm{~m}$ to $0.6 \mathrm{~m}$. When the viewing distance reached $1.2 \mathrm{~m}$, the pupil size decreased significantly. When the viewing distance reached $2.285 \mathrm{~m}$, the above two observation methods were very close to the pupil size obtained using the double mirror system, which was about $4.19 \pm 0.07 \mathrm{~mm}$. The results indicate that the accommodative response and pupil size are consistent throughout these three methods at a viewing distance of $2.285 \mathrm{~m}$. The advantage of this optical design is that the object can be seen at a longer distance, and the enlarged image is easier to observe. Compared to single plane mirror imaging, the image is in the opposite orientation, from left to the right, and the double-mirror system has no such problem.

Table 2. The accommodative response varies with the viewing distance in the different ways.

\begin{tabular}{ccccccc}
\hline \multirow{2}{*}{$\begin{array}{c}\text { Accommodative } \\
\text { Response (D) }\end{array}$} & $\mathbf{5}$ Viewing Distance (m) \\
\cline { 2 - 7 } & $\mathbf{0 . 4}$ & $\mathbf{0 . 6}$ & $\mathbf{0 . 8}$ & $\mathbf{1 . 2}$ & $\mathbf{1 . 6}$ & $\mathbf{2 . 2 8 5}$ \\
\hline Directly seeing target & $1.69 \pm 0.31$ & $0.74 \pm 0.22$ & $0.48 \pm 0.09$ & $0.37 \pm 0.08$ & $0.14 \pm 0.05$ & $0.11 \pm 0.04$ \\
Single plane mirror & $1.97 \pm 0.59$ & $1.20 \pm 0.31$ & $0.83 \pm 0.16$ & $0.26 \pm 0.06$ & $0.17 \pm 0.03$ & $0.16 \pm 0.04$ \\
Double-mirror system & $\mathrm{x}$ & $\mathrm{x}$ & $\mathrm{x}$ & $\mathrm{x}$ & $\mathrm{x}$ & $0.11 \pm 0.05$ \\
\hline
\end{tabular}

Note: The viewing distance of the double-mirror system is fixed-there is only one distance. Accommodative response at $2.285 \mathrm{~m}$.

\subsection{Fluctuations in Accommodation}

Figure 6 plots the fluctuations of the accommodative responses of 5 subjects gazing at a real object at a distance of $0.4 \mathrm{~m}$, and gazing at a virtual image at a distance of $2.285 \mathrm{~m}$ for $30 \mathrm{~s}$. The corresponding refractive corrections were $-0.5,-1,-2,-3$, and $-4 \mathrm{D}$, respectively. It is evident that although there is a considerable variation in the amplitude of accommodative fluctuations among the subjects, the fluctuations of the 5 subjects were small when at a viewing distance of $2.285 \mathrm{~m}$ through the double-mirror system. Moreover, the fluctuations increased at a viewing distance of $0.4 \mathrm{~m}$. It is worth noting that the double-mirror system not only contributed to the accommodative relaxation, but also to the stability of the accommodation fluctuations. 


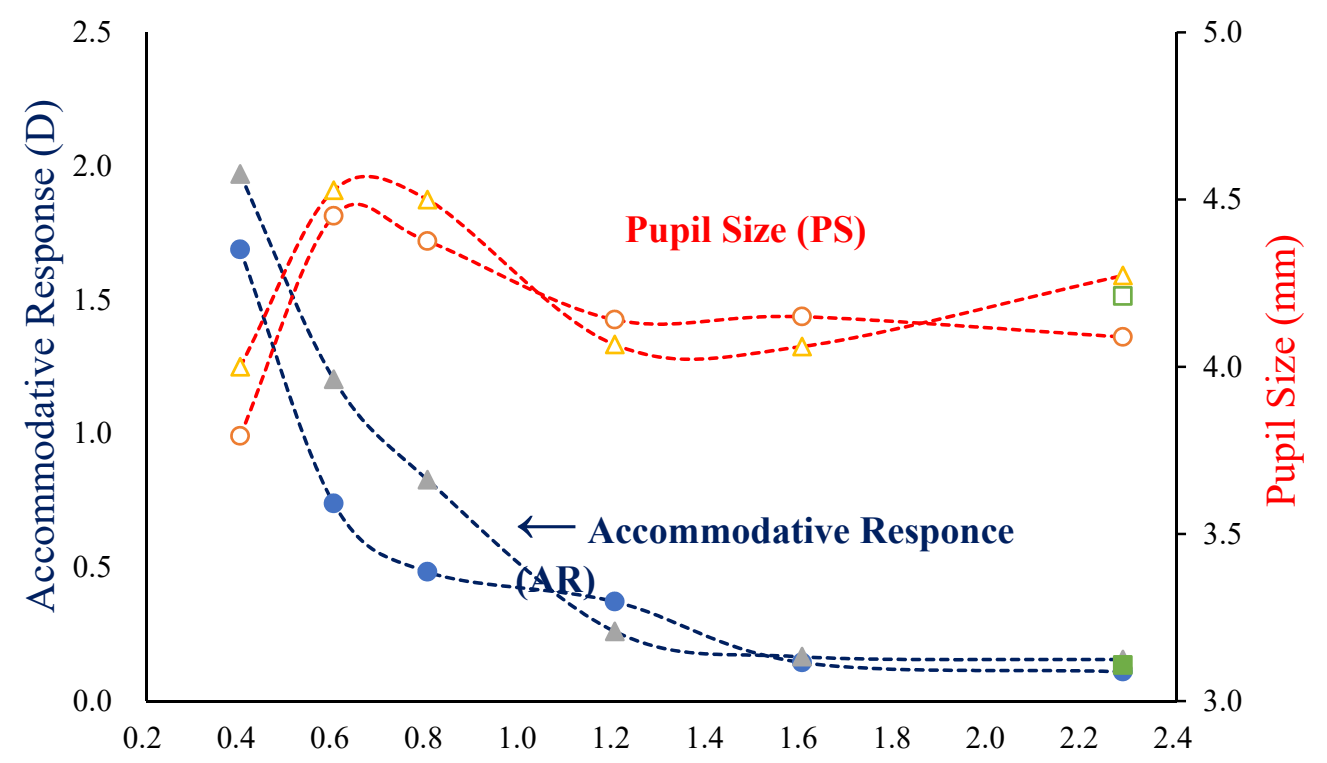

Viewing Distance (m)
AR_----.- Directly seeing target
----.-. Plane Mirror
- Double Mirror
PS ---O--. Directly seeing target
$---\triangle-\cdot$ Plane Mirror
$\square \quad$ Double Mirror

Figure 5. Dependence of the accommodative response and pupil size on the viewing distance with (1) directly seeing the real object, (2) seeing the virtual image through a single plane mirror, and (3) seeing the virtual image at $2.285 \mathrm{~m}$ through the double-mirror system. A solid circle, a solid triangle and a solid square represent the accommodative response, while a hollow circle, a hollow triangle and a hollow square represent the pupil size corresponding to (1-3).

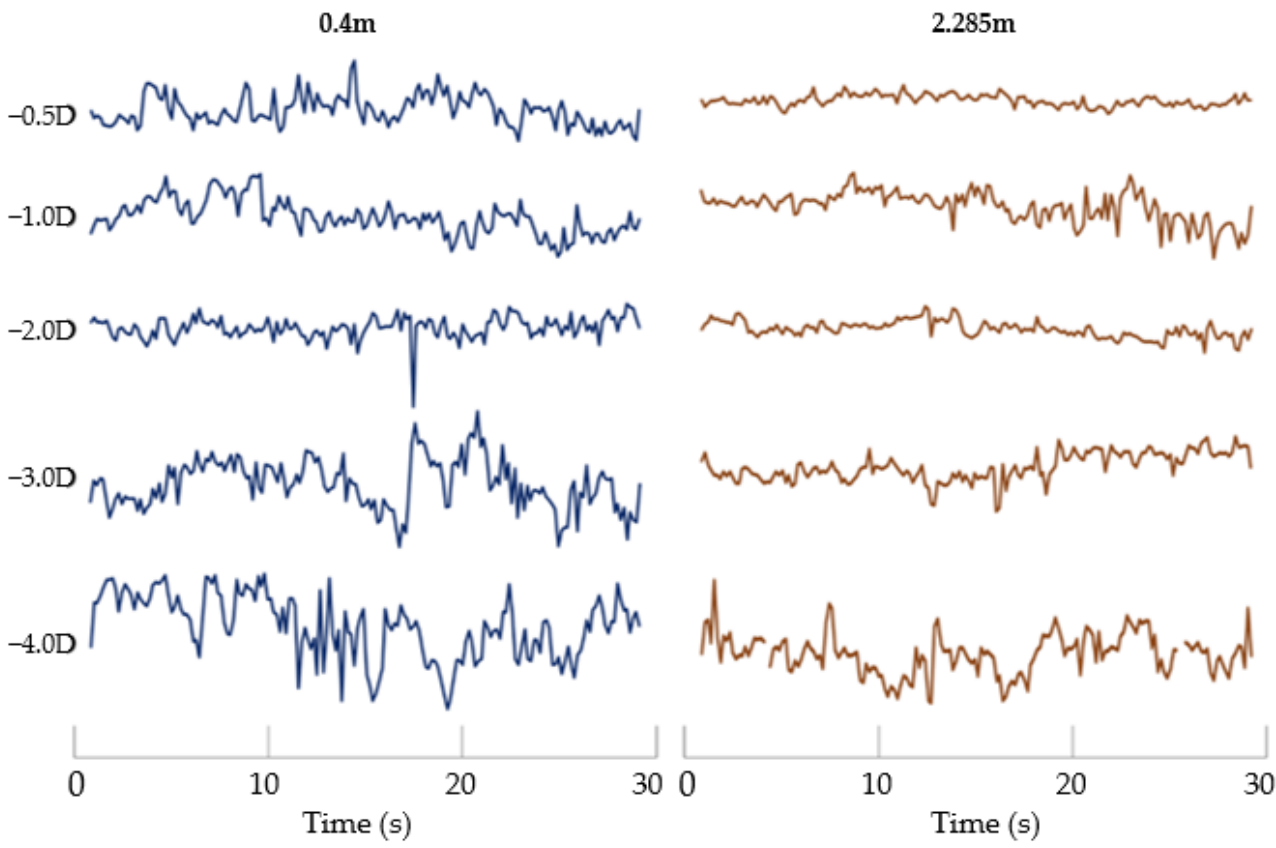

Figure 6. The fluctuations of the accommodation response for 5 subjects gazing at a real object at $0.4 \mathrm{~m}$ and gazing at a virtual image at $2.285 \mathrm{~m}$ for $30 \mathrm{~s}$. The corresponding refractive corrections are $-0.5,-1,-2,-3$, and $-4 \mathrm{D}$, respectively. 


\section{Conclusions}

This study proposed a new simple optical design with a double-mirror system to extend viewing distance to $2.285 \mathrm{~m}$ and to magnify the image up to $3.386 \mathrm{X}$. The results confirm that the accommodative response decreased and that the pupil size increased significantly at a viewing distance of $2.285 \mathrm{~m}$ through the double-mirror system. The mean value of the accommodative response can be reduced to $0.11 \pm 0.05 \mathrm{D}$, and the fluctuations of the accommodative response can also be stabilized. In this study, the accommodative response of the subjects aged from 18 to 22 years old can be reduced by the simple optical design. We expect that accommodative relaxation can be also achieved for school children. Moreover, it may have the potential application in slowing down the progression of myopia and to mitigate the problems caused by near work.

Author Contributions: Conceptualization, S.-M.Y. and S.-Y.H.; investigation, H.-R.S.; resources, S.-M.Y. and S.-Y.H.; data curation, H.-R.S.; formal analysis, H.-R.S., C.-H.L. and Y.-J.C.; software, C.-H.L.; writing—original draft preparation, S.-M.Y.; writing—review and editing, S.-Y.H. All authors have read and agreed to the published version of the manuscript.

Funding: This research was funded by Ministry of Science and Technology (MOST) of Taiwan under Grant MOST 107-2218-E-040-001, and the Chung Shan Medical University research project (G107N01) in Taiwan.

Institutional Review Board Statement: The study was conducted according to the guidelines of the Declaration of Helsinki, and approved by the Ethics Committee of Chung Shan Medical University Hospital (Taichung, Taiwan) (Approval number: CS2-18104).

Data Availability Statement: The datasets used during the current study are available from the corresponding author.

Acknowledgments: We are grateful to Hsi-Hsun Chen from E-Lead Electronic Co., Ltd. for assistance with optical design and assembly technique.

Conflicts of Interest: The authors declare no conflict of interest.

\section{References}

1. Misra, S.; Cheng, L.; Genevie, J.; Yuan, M. The iPhone effect: The quality of in person social interactions in the presence of mobile devices. Environ. Behav. 2016, 48, 275. [CrossRef]

2. Demir, P.; Baskaran, K.; Theagarayan, B.; Gierow, P.; Sankaridurg, P.; Macedo, A.F. Refractive error, axial length, environmental and hereditary factors associated with myopia in Swedish children. Clin. Exp. Optom. 2021, 2, 1.

3. Guan, H.; Yu, N.N.; Wang, H.; Boswell, M.; Shi, Y.; Rozelle, S.; Congdon, N. Impact of various types of near work and time spent outdoors at different times of day on visual acuity and refractive error among Chinese school-going children. PLoS ONE 2019, 14, 1. [CrossRef] [PubMed]

4. Deng, L.; Gwiazda, J.; Thorn, F. Children's refractions and visual activities in the school year and summer. Optom. Vis. Sci. 2010, 87, 406. [CrossRef]

5. Hagen, L.A.; Gjelle, J.V.B.; Arnegard, S.; Pedersen, H.R.; Gilson, S.J.; Baraas, R.C. Prevalence and possible factors of myopia in Nnorwegian adolescents. Sci. Rep. 2018, 8, 1. [CrossRef]

6. Stokols, D.; Misra, S.; Runnerstrom, M.G.; Hipp, J.A. Psychology in an age of ecological crisis: From personal angst to collective action. Am. Psychol. 2009, 64, 181. [CrossRef] [PubMed]

7. Ophir, E.; Nass, C.; Wagner, A.D. Cognitive control in media multitaskers. Proc. Natl. Acad. Sci. USA 2009, 1, 15583. [CrossRef] [PubMed]

8. Lee, Y.Y.; Lo, C.T.; Sheu, S.J.; Lin, J.L. What factors are associated with myopia in young adults? A Survey Study in Taiwan Military Conscripts. Investig. Ophthalmol. Vis. Sci. 2013, 54, 1026. [CrossRef]

9. Mutti, D.O.; Mitchell, G.L.; Moeschberger, M.L.; Jones, L.A.; Zadnik, K. Parental myopia, near work, school achievement, and children's refractive error. Investig. Ophthalmol. Vis. Sci. 2002, 43, 3633.

10. Saw, S.M.; Hong, R.Z.; Zhang, M.Z.; Fu, Z.F.; Ye, M.; Tan, D.; Chew, S.J. Near-work activity and myopia in rural and urban schoolchildren in China. J. Pediatric Ophthalmol. Strabismus 2001, 38, 149. [CrossRef]

11. García-Gen, E.; Penadés, M.; Mérida, S.; Desco, C.; Araujo-Miranda, R.; Navea, A.; Bosch-Morell, F. High Myopia and the Complement System: Factor H in Myopic Maculopathy. J. Clin. Med. 2021, 10, 2600. [CrossRef]

12. Aikaterini, I. Moulakaki. Assessing the accommodation response after near visual tasks using different handheld electronic devices. Arq. Bras. Oftalmol. 2017, 80, 9. 
13. Chu, C.A.; Rosenfield, M.; Portello, J.K. Computer Vision Syndrome: Blink Rate and Dry Eye during Hard Copy or Computer Viewing. Investig. Ophthalmol. Vis. Sci. 2010, 51, 957.

14. Blehm, C.G.; Vishnu, S.; Dawson, K.; Chuang, A.; Yee, R. Ocular Surface Analysis and Treatment in Computer Vision Syndrome. Investig. Ophthalmol. Vis. Sci. 2004, 45, 3912.

15. Hayes, J.R.; Sheedy, J.E.; Stelmack, J.A.; Heaney, C.A. Computer use, symptoms, and quality of life. Optom. Vis. Sci. Off. Publ. Am. Acad. Optom. 2007, 84, 738. [CrossRef]

16. Mazyed Alsaqr, A.; Alshareef, H.; Alhajri, F.; Abusharha, A.; Fagehi, R.; Alharbi, A.; Alanazi, S. Accommodative Response in Patients with Central Field Loss: A Matched Case-Control Study. Vision 2021, 5, 35. [CrossRef] [PubMed]

17. Sheppard, A.L.; Wolffsohn, J.S. Digital eye strain: Prevalence, measurement and amelioration. BMJ Open Ophthalmol. 2018, 3, e000146. [CrossRef]

18. Rosenfield, M. Computer vision syndrome (a.k.a. digital eye). Optom. Pract. 2016, 17, 1.

19. Yuda, K. Training regimen involving cyclic induction of pupil constriction during far accommodation improves visual acuity in myopic children. Clin. Ophthalmol. 2010, 4, 251.

20. Iwasaki, T.; Tawara, A.; Miyake, N. Reduction of asthenopia related to accommodative relaxation bymeans of far point stimuli. Acta Ophthalmol. Scand 2005, 83, 81. [CrossRef]

21. LightTools. Available online: https://www.synopsys.com/optical-solutions/lighttools.html (accessed on 23 July 2021).

22. Park, S.M.; Moon, B.Y.; Kim, S.Y.; Yu, D.S. Diurnal variations of amplitude of accommodation in different age groups. PLoS ONE 2019, 14, e0225754. [CrossRef] 